\title{
Improved Learning Achievement About How to Introduce Oneself Through the Scientific Approach of Video Media
}

\author{
Istina Dewi Puji Astuti \\ SD Negeri Plosogede 1 \\ istina160382@gmail.com
}

\section{Article History}

accepted $14 / 11 / 2020$

approved $21 / 11 / 2020$

published 26/11/2020

\begin{abstract}
The purpose of this study was to improve the learning achievement of students in Indonesian Language Mupel in Elementary Class 1 through a scientific approach with video media. The research conducted was a Classroom Action Research (CAR )in three cycles, which each cycle consisting of one meeting. The stage of each cycle are planning, implementing, observing and reflecting. Each meeting is carried out a pre test and post test to determine the progress of students. In the first cycle students who completed after carrying out the post test were $50 \%$. In the second cycle students who completed after carrying out the post test were $85,71 \%$. In the third cycle students who completed after carrying out the post test were 92,85\%. These results indicate that learning through a scientifik approach with video media can improve student learning achievement, especially Mupel Indonesian Language on How to Introduce Yourself in Class 1 SDN Plosogede 1.
\end{abstract}

Keywords: learning achievement, Video media, Indonesian language

\begin{abstract}
Abstrak
Tujuan dari penelitian ini adalah untuk meningkatkan prestasi belajar peserta didik pada Mupel Bahasa Indonesia di Sekolah Dasar Kelas 1 melalui pendekatan Saintifik dengan media video.Penelitian yang dilakukan adalah Penelitian Tindakan Kelas (PTK) sebanyak tiga siklus, dengan setiap siklusnya terdiri dari satu pertemuan. Tahapan setiap siklusnya adalah perencanaan, pelaksanaan, observasi dan refleksi. Setiap pertemuan dilakukan pre test dan post test untuk mengetahui perkembangan peserta didik. Pada siklus I peserta didik yang tuntas setelah melaksanakan post test sebesar $50 \%$. Pada siklus II peserta didik yang tuntas setelah melaksanakan post test sebesar $85,71 \%$. Pada siklus III peserta didik yang tuntas setelah melaksanakan post test sebesar $92,85 \%$. Hasil ini menunjukkan bahwa pembelajaran melalui pendekatan saintifik dengan media video dapat meningkatkan prestasi belajar peserta didik khususnya Mupel Bahasa Indonesia Materi Cara Memperkenalkan Diri Kelas 1 SDN Plosogede 1
\end{abstract}

Kata kunci: prestasi belajar,media video, bahasa indonesia

Social, Humanities, and Education Studies (SHEs): Conference Series https://jurnal.uns.ac.id/shes

p-ISSN 2620-9284

e-ISSN 2620-9292 


\section{PENDAHULUAN}

Pendidikan memiliki peranan yang besar dalam mensukseskan pembangunan bangsa karena pendidikan merupakan kebutuhan pokok setiap manusia. Oleh karena itu pemerintah beserta unsur-unsurnya yang profesional dan kompeten di dalamnya harus benar-benar memperbaiki dan mengembangkan pendidikan menuju kemajuan pendidikan di Indonesia pada umumnya. Secara umum pendidikan adalah proses pembelajaran pengetahuan, keterampilan serta kebiasaan yang dilakukan individu dari satu generasi ke generasi lainnya. Proses pembelajarn melalui pengajaran, pelatihan dan penelitian. Pendidikan dapat meningkatkan kecerdasan, kepribadian, akhlaq yang baik serta keterampilan yang bermanfaat untuk diri sendiri maupun orang lain.

Prestasi adalah hal yang telah dicapai seseorang dalam melakukan kegiatan. Gagne (1985:40) menyatakan bahwa prestasi belajar dibedakan menjadi lima aspek: kemampuan intelektual, strategi kognitif, informasi verbal, sikap dan ketrampilan. Menurut Bloom dlam Suharsimi Arikunto (1990:110) bahwa hasil belajar dibedakan menjadi tiga aspek yaitu kognitif, afektif, dan psikomotorik.

Sebagian besar peserta didik kelas rendah mengalami kesulitan dalam memahami pelajaran karena tidak melihat kondisi riil yang terdapat pada materi sehingga sulit bagi mereka untuk menerima materi pelajaran ; dari hasil wawancara dengan siswa diketahui bahwa siswa merasa jenuh dengan pembelajaran yang dirasa monoton; guru juga masih melakukan pembelajaran dengan teks book oriented; media pembelajaran yang dipakai juga masih tergolong konvensional dan kurang menarik minat siswa ; saat proses pembelajaran siswa kurang tertarik untuk menerima materi. Dari indikator masalah di atas berujung pada hasil evaluasi yang kurang memuaskan. Oleh karena itu diperlukan strategi-strategi khusus agar proses pembelajaran berjalan lancer dan menyenangkan. Guru sebagai komponen penting dari tenaga kependidikan harus inovatif. Dalam hal ini, guru harus mempunyai beberapa strategi pembelajaran agar proses belajar tidak membosankan bagi anak. Pembelajaran berarti upaya membelajarkan siswa (Degeng, 1989). Dengan demikian, strategi pembelajaran berarti cara dan seni untuk menguraikan sumber belajar dalam upaya membelajarkan siswa.Strategi pembelajaran sangat diperlukan untuk mendapatkan hasil yang optimal.

Berdasarkan kajian terhadap masalah di atas, maka solusi yang ingin diambil adalah bagaimana membuat anak tertarik untuk mengikuti pembelajaran serta memahami materi secara maksimal. Dalam hal ini, penelitian ini difokuskan pada penggunaan media yang tepat sebagai upaya perbaikan pembelajaran tematik agar anak lebih berminat mengikuti pelajaran. Media yang dirasa cocok dan dapat mempertinggi minat siswa adalah multi media video. Video merupakan serangkaian gambar gerak yang disertai suara yang membentuk suatu kesatuan yang dirangkai menjadi alur, dengan pesan-pesan di dalamnya untuk ketercapaian tujuan pembelajaran yang disimpan dengan proses penyimpanan pada media pita atau disk (Arsyad, 2004:36 dalam Rusman dkk 2011:218). Video merupakan media audio visual yang menampilkan gerak (Sadiman, 2008:74). Kelebihan Media Video Pembelajaran Mengatasi jarak dan waktu, mampu menggambarkan peristiwa-peristiwa masa lalu secara realistis dalam waktu yang singkat, dapat membawa siswa berpetualang dari negara satu ke negara lainnya dan dari masa yang satu ke masa yang lain, dapat diulang-ulang bila perlu untuk menambah kejelasan, pesan yang disampaikannya cepat dan mudah diingat, mengembangkan pikiran dan pendapat para siswa, mengembangkan imajinasi, memperjelas hal-hal yang abstrak memberikan penjelasan yang lebih realistic, mampu berperan sebagai media utama untuk mendokumentasikan realitas sosial yang akan dibedah di dalam kelas, mampu berperan sebagai storyteller yang dapat memancing kreativitas peserta didik dalam mengekspresikan gagasannya. Kelemahan Media Video Pembelajaran adalah sebagaimana media audio-visual yang lain, video juga terlalu menekankan pentingnya materi ketimbang proses pengembangan materi tersebut; pemanfaatan media ini juga terkesan memakan biaya 
tidak murahdan penanyangannya juga terkait peralatan lainnya seperi videoplayer, layar bagi kelas besar beserta LCDnya, dan lain-lain.

Tujuan penelitian ini adalah untuk meningkatkan prestasi belajar tentang cara memperkenalkan diri melalui pendekatan saintifik dengan media Video pada siswa kelas 1 SDN Plosogede 1 Kecamatan Ngluwar, Kabupaten Magelang.

\section{METODE}

Penelitian ini adalah penelitian tindakan kelas (Classroom Action Research) dengan menerapkan pendekatan Saintifik melalui media video. Menurut Kurt Lewin dalam Kunandar (2011: 42) penelitian tindakan kelas ini terdiri dari empat tahapan dasar yaitu perencanaan (planning), pelaksanaan (acting), pengamatan (observing) dan refleksi (reflecting). Analisis penelitian ini adalah analisis deskriptif kuantitafif kualitatif dimana dalam penelitian ini selain penyajian hasil berupa data maupun angka peneliti juga menentukan bagaimana cara pengolahan hasil penelitian yakni dengan membuat analisisnya dengan menerapkan pendekatan Saintifik melalui media video. Penelitian ini dilaksanakan pada peserta didik kelas I SD Negeri Plosogede 1 Tahun Pelajaran 2020/2021 selama tiga siklus secara luring dengan satu pertemuan disetiap siklusnya. Siklus I dilaksanakan pada tanggal 2 November 2020. Siklus II dilaksanakan pada tanggal 9 November 2020. Siklus III dilaksanakan pada tanggal 20 November 2020. Teknik pengumpulan data yang dilakukan dengan observasi , tes prestasi dan wawancara. Observasi meliputi observasi aktifitas peserta didik, keterampilan dan pengetahuan.

\section{HASIL DAN PEMBAHASAN}

Pada siklus I pembelajaran dilaksanakan selama satu pertemuan, setiap pertemuan diadakan pre test dan post test. Untuk mengetahui perkembangan peserta didik selama pembelajaran. Siklus I membahas materi tentang cara memperkenalkan diri, berupa kelancaran, kejelasan suara, runtt dan percaya diri. Pembelajaran melalui pendekatan Saintifik dengan media video dilaksanakan kegiatan pembelajaran sesuai dengan tahapan pembelajaran permulaan dengan menggunakan media video yang telah dipersiapkan dalam perencanaan. Selama proses pembelajaran berlangsung, peneliti sekaligus guru kelas 1 mengajar sesuai dengan Rencana Pelaksanaan Pembelajaran (RPP) yang telah dibuat dibantu dengan guru pamong dalam melakukan observasi terhadap peserta didik selama kegiatan pembelajaran berlangsung. Tahaptahapnya yaitu kegiatan awal, kegiatan inti dan kegiatan akhir. Berikut ini adalah hasil belajar peserta didik pada siklus I yang bisa dilihat pada tabel berikut.

Tabel 1. Hasil Belajar Peserta Didik Siklus I

\begin{tabular}{lcccccccc}
\hline \multirow{2}{*}{ Siklus 1 } & \multicolumn{3}{c}{ Pre test } & \multicolumn{2}{c}{ Post test } \\
\cline { 2 - 9 } & $\begin{array}{c}\text { Pesdik } \\
\text { Tuntas }\end{array}$ & $\begin{array}{c}\text { Pesdik belum } \\
\text { tuntas }\end{array}$ & \multicolumn{2}{c}{$\begin{array}{c}\text { Pesdik } \\
\text { Tuntas }\end{array}$} & \multicolumn{2}{c}{$\begin{array}{c}\text { Pesdik } \\
\text { belum tuntas }\end{array}$} \\
\hline & $\mathrm{Jml}$ & $\%$ & $\mathrm{Jml}$ & $\%$ & $\mathrm{Jml}$ & $\%$ & $\mathrm{Jml}$ & $\%$ \\
\hline & 4 & 29 & 10 & 71 & 7 & 50 & 7 & 50 \\
\hline
\end{tabular}


SHEs: Conference Series 3 (3) (2020) 856- 862

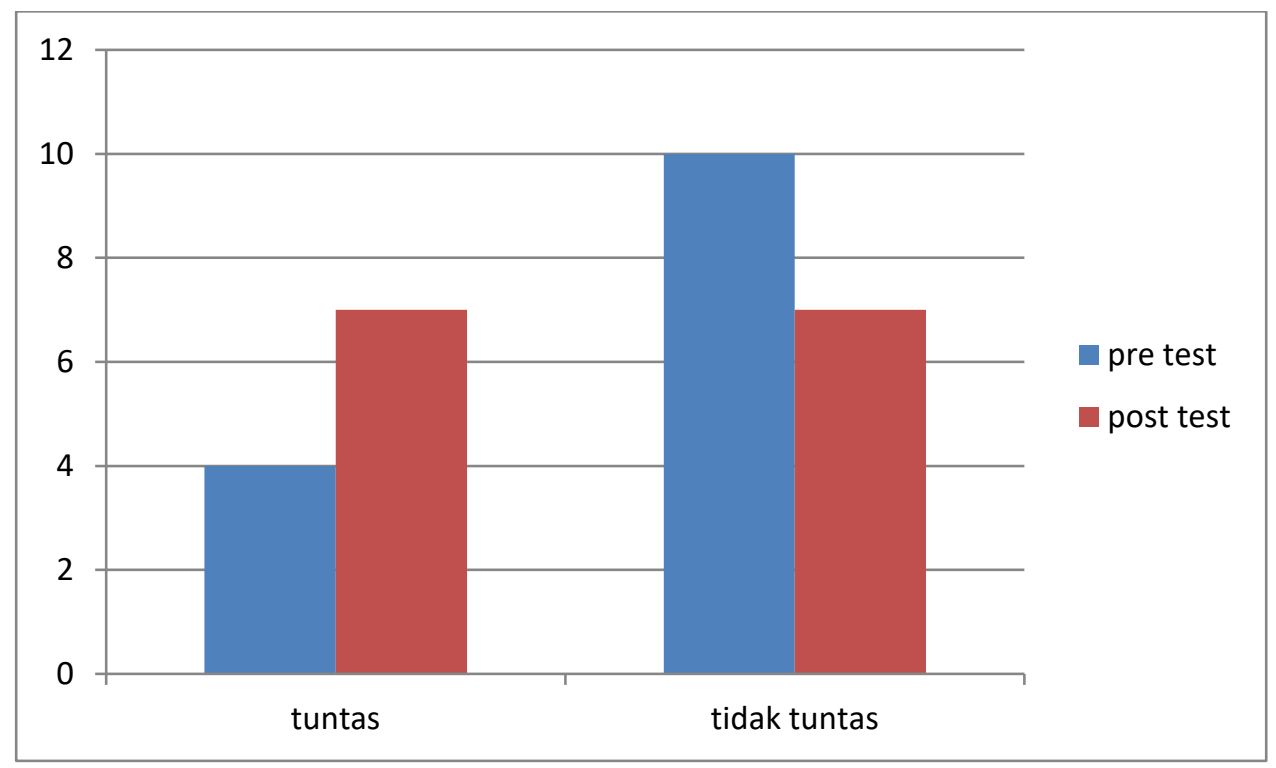

Gambar 1. Hasil Observasi Pengetahuan Siklus 1

Berdasarkan tabel di atas maka terjadi peningkatan antara pre test dan post test pada siklus I. Setiap individu peserta didik sudah mengalami peningkatan hasil belajarnya. Ketuntasan klasikal juga mengalami peningkatan, pada pre test hanya terdapat 4 anak yang sudah tuntas, tetapi pada post test bertambah menjadi 7 anak yang sudah tuntas dengan Kriteria Ketuntasan Minimal (KKM) sebesar 75. Persentase ketuntasan klasikalnya meningkat, jika pada pre test hanya $29 \%$ maka pada post test menjadi $50 \%$.

Berdasarkan refleksi pada siklus I maka diputuskan untuk melanjutkan ke siklus II dikarenakan belum mencapai ketuntasan klasikal yang diharapkan. Siklus II membahas materi tentang cara memperkenalkan diri menggunakan pendekatan saintifik melalui media video. Pembelajaran dengan media video denagn langkahlangkah pembelajaran yaitu Kegiatan awal, Kegiatan inti dan penutup Berikut ini adalah hasil belajar peserta didik pada siklus II yang bisa dilihat pada tabel berikut.

Tabel 2. Hasil Belajar Peserta Didik Siklus II

\begin{tabular}{ccccccccc}
\hline \multirow{3}{*}{ Siklus 2 } & \multicolumn{3}{c}{ Pre test } & \multicolumn{2}{c}{ Post test } \\
\cline { 2 - 9 } & \multicolumn{2}{c}{$\begin{array}{c}\text { Pesdik } \\
\text { Tuntas }\end{array}$} & $\begin{array}{c}\text { Pesdik belum } \\
\text { tuntas }\end{array}$ & \multicolumn{2}{c}{$\begin{array}{c}\text { Pesdik } \\
\text { Tuntas }\end{array}$} & $\begin{array}{c}\text { Pesdik } \\
\text { belum tuntas }\end{array}$ \\
\hline & $\mathrm{Jml}$ & $\%$ & $\mathrm{Jml}$ & $\%$ & $\mathrm{Jml}$ & $\%$ & $\mathrm{Jml}$ & $\%$ \\
\hline & 8 & 57 & 6 & 43 & 12 & 86 & 2 & 14 \\
\hline
\end{tabular}


SHEs: Conference Series 3 (3) (2020) 856- 862

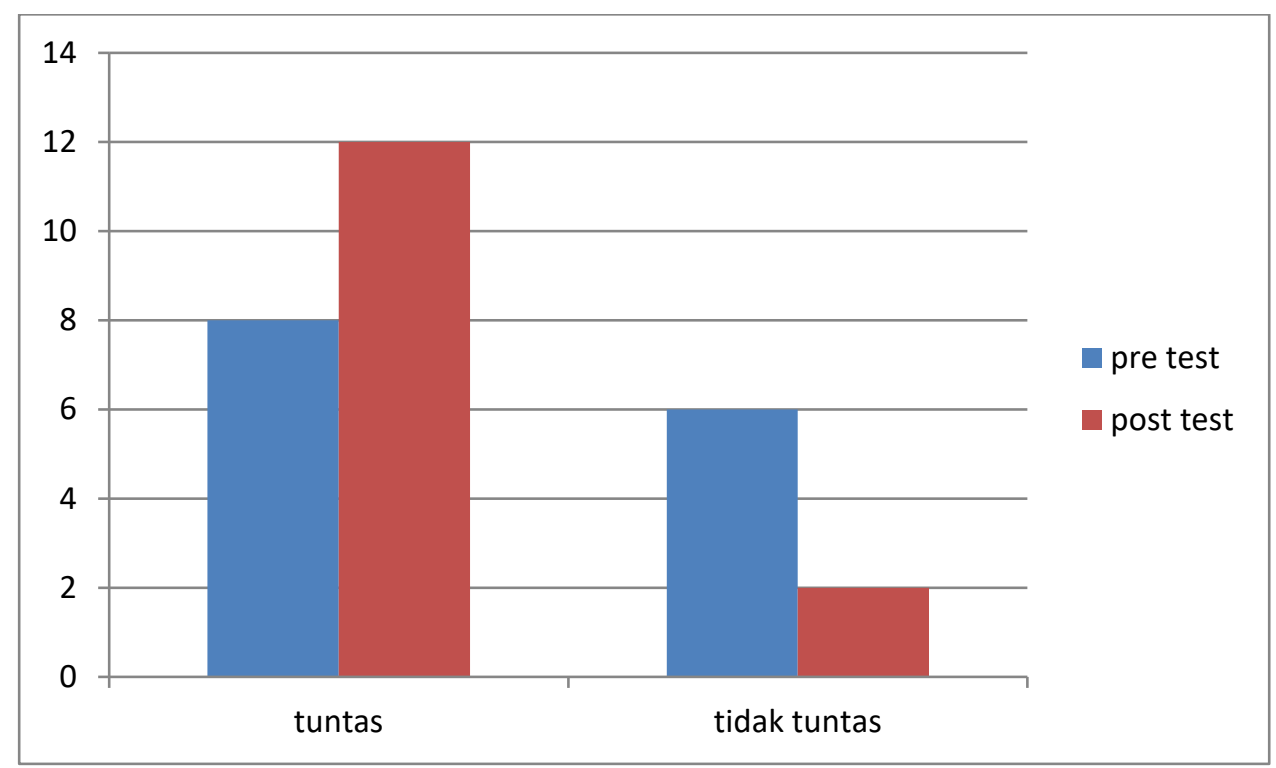

Berdasarkan tabel di atas maka terjadi peningkatan antara pre test dan post test pada siklus II. Setiap individu peserta didik sudah mengalami peningkatan hasil belajarnya. Ketuntasan klasikal juga mengalami peningkatan, pada pre test hanya terdapat 8 anak yang sudah tuntas, tetapi pada post test bertambah menjadi 12 anak yang sudah tuntas dengan Kriteria Ketuntasan Minimal (KKM) sebesar 75. Persentase ketuntasan klasikalnya meningkat, jika pada pre test hanya $57 \%$ maka pada post test menjadi $86 \%$.

Setelah melakukan refleksi pada siklus II, maka diputuskan untuk melanjutkan ke siklus III. Hal ini dilakukan agar mengetahui sejauh mana pembelajaran melalui pendekatan Saintifik dengan media video tidak hanya meningkatkan prestasi belajar tetapi juga mempertahankan prestasi belajar peserta didik. Pada siklus III materi yang diajarkan adalah cara memperkenalkan diri menggunakan media video dan simulasi perkenalan diri menggunakan foto keluarga. Langkah-langkah pembelajarannya yaitu Kegiatan awal, Kegiatan inti dan penutup. Hasil belajar peserta didik pada siklus III yang bisa dilihat pada tabel berikut.

Tabel 3. Hasil Belajar Peserta Didik Siklus III

\begin{tabular}{lcccccccc}
\hline \multirow{2}{*}{ Siklus 3 } & \multicolumn{3}{c}{ Pre test } & \multicolumn{2}{c}{ Post test } \\
\cline { 2 - 9 } & $\begin{array}{r}\text { Pesdik } \\
\text { Tuntas }\end{array}$ & \multicolumn{2}{c}{$\begin{array}{c}\text { Pesdik belum } \\
\text { tuntas }\end{array}$} & \multicolumn{2}{c}{$\begin{array}{c}\text { Pesdik } \\
\text { Tuntas }\end{array}$} & $\begin{array}{c}\text { Pesdik } \\
\text { belum tuntas }\end{array}$ \\
\hline & Jml & $\%$ & $\mathrm{Jml}$ & $\%$ & $\mathrm{Jml}$ & $\%$ & $\mathrm{Jml}$ & $\%$ \\
\hline & 10 & 71 & 4 & 29 & 13 & 93 & 1 & 7 \\
\hline
\end{tabular}




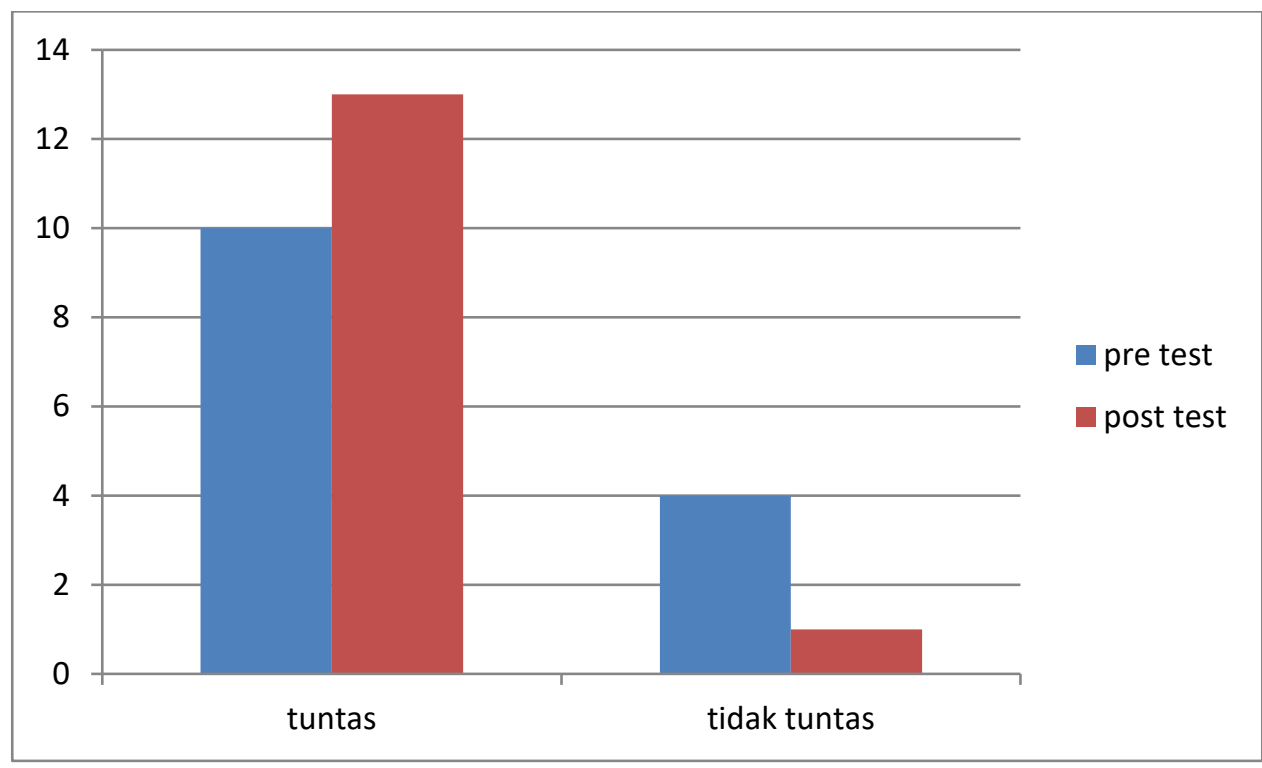

Berdasarkan tabel di atas maka terjadi peningkatan antara pre test dan post test pada siklus III. Setiap individu peserta didik sudah mengalami peningkatan hasil belajarnya. Ketuntasan klasikal juga mengalami peningkatan, pada pre test hanya terdapat 10 anak yang sudah tuntas, tetapi pada post test bertambah menjadi 13 anak yang sudah tuntas dengan Kriteria Ketuntasan Minimal (KKM) sebesar 75. Persentase ketuntasan klasikalnya meningkat, jika pada pre test hanya $71 \%$ maka pada post test menjadi $93 \%$.

Dari tiga siklus yang sudah dilaksanakan selama 3 pertemuan dapat dilihat bahwa melalui pendekatan Saintifik dengan media video dapat meningkatkan prestasi belajar peserta didik pada mupel Bahasa Indonesia Kelas I di SD Negeri Plosogede 1. Pada Siklus I ketuntasan klasikalnya sebesar $50 \%$, pada siklus II sebesar $86 \%$, dan pada siklus III sebesar $93 \%$.

\section{SIMPULAN}

Berdasarkan data di atas maka dapat disimpulkan bahwa penerapan pendekatan pembelajaran Saintifik dengan media video dapat meningkatkan prestasi belajar peserta didik Kelas I pada mupel Bahasa Indonesia materi cara memperkenalkan diri. Peningkatan yang terjadi karena adanya kesan yang mendalam dari peserta didik terhadap materi yang diajarkan melalui media video. Peserta didik menjadi lebih teringat karena mempraktikkan perkenalan diri secara langsung berdasarkan video yang mereka amati. Berdasarkan penelitian yang telah dilaksanakan penggunaaan media pembelajaran yang cocok diterapkan dalam kegiatan pembelajaran adalah media video karena lebih menarik dan mudah digunakan.

\section{DAFTAR PUSTAKA}

Arikunto, Suharsimi. (1990). Dasar-Dasar Evaluasi Pendidikan. Jakarta : Bumi Aksara Arikunto, Suharsimi ,dkk. (2009). Penelitian Tindak Kelas. Jakarta: Bumi Aksara

Arikunto, Suharsimi. 2016. Prosedur Penelitian: Suatu Pendekatan Praktik. Jakarta: Rineka Cipta

Degeng, I. N. S. (1989). IImu Pengajaran Taksonomi Variable. Jakarta : Depdikbud

Gagne.1985. Pengertian Belajar. Dalam Winataputra S. Putra. Teori Belajar dan Pembelajaran. Jakarta: Universitas Terbuka. 
SHEs: Conference Series 3 (3) (2020) 856- 862

Kunandar. (2011). Langkah Mudah Penelitian Tindakan Kelas Sebagai Pengembangan Profesi Guru. Jakarta : Rajawali Pres.

Rusman. 2015. Pembelajaran Tematik Terpadu. Jakarta: Raja Grafindo Persada.

Sadiman, S. Arief. 2006. Media pendidikan: Pengertian, pengembangan dan pemanfaatannya. Jakarta: PT Raja Grafindo Persada. 